\title{
First Detection of GES-5-Producing Escherichia coli from Livestock-An Increasing Diversity of Carbapenemases Recognized from German Pig Production
}

\author{
Alexandra Irrgang ${ }^{1, *(\mathbb{D}}$, Simon H. Tausch ${ }^{1} \mathbb{D}$, Natalie Pauly ${ }^{1}$, Mirjam Grobbel ${ }^{1} \mathbb{D}$, \\ Annemarie Kaesbohrer ${ }^{1,2}$ and Jens A. Hammerl ${ }^{1}$ (D) \\ 1 Department Biological Safety, German Federal Institute for Risk Assessment (Bundesinstitut für \\ Risikobewertung, BfR), D-10589 Berlin, Germany; simon.tausch@bfr.bund.de (S.H.T.); \\ natalie.pauly@bfr.bund.de (N.P.); mirjam.grobbel@bfr.bund.de (M.G.); \\ annemarie.kaesbohrer@bfr.bund.de (A.K.); jens-andre.hammerl@bfr.bund.de (J.A.H.) \\ 2 Institute for Veterinary Public Health, University of Veterinary Medicine, 1210 Vienna, Austria \\ * Correspondence: alexandra.irrgang@bfr.bund.de; Tel.: +49-30-18412-24310
}

Received: 29 September 2020; Accepted: 14 October 2020; Published: 16 October 2020

\begin{abstract}
Resistance to carbapenems due to carbapenemase-producing Enterobacteriaceae (CPE) is an increasing threat to human health worldwide. In recent years, CPE could be found only sporadically from livestock, but concern rose that livestock might become a reservoir for CPE. In 2019, the first GES carbapenemase-producing Escherichia coli from livestock was detected within the German national monitoring on antimicrobial resistance. The isolate was obtained from pig feces and was phenotypically resistant to meropenem and ertapenem. The isolate harbored three successive $b a_{\mathrm{GES}}$ genes encoding for GES-1, GES-5 and GES-5B in an incomplete class-I integron on a $12 \mathrm{~kb}$ plasmid (pEC19-AB02908; Acc. No. MT955355). The strain further encoded for virulence-associated genes typical for uropathogenic $E$. coli, which might hint at an increased pathogenic potential. The isolate produced the third carbapenemase detected from German livestock. The finding underlines the importance $\mathrm{CPE}$ monitoring and detailed characterization of new isolates.
\end{abstract}

Keywords: carbapenemase; CPE; GES-5; GES-5B; whole-genome sequencing; livestock

\section{Introduction}

Carbapenemase-producing Enterobacteriaceae (CPE) are a global threat to human health. Carbapenemases are often associated with nosocomial infections (esp. KPC) but are also disseminated in the community [1]. While OXA-48, VIM, NDM and KPC carbapenemases are detected frequently from human infections in Germany, GES carbapenemase-producing bacteria were only isolated sporadically [2]. In 2018, bla $a_{\mathrm{GES}}$ carbapenemase genes were recovered from 5 Enterobacteria and 14 Pseudomonas aeruginosa isolates from human infections, representing 1\% of detected CPE from human infections in Germany [2]. GES enzymes are serine proteases of the Ambler class A [3]. GES-1 was first described in Klebsiella pneumoniae. It exhibits strong activity against most $\beta$-lactams and results in an extended-spectrum $\beta$-lactamase (ESBL) phenotype [4]. Point mutations can lead to increased hydrolyzing activity and carbapenem substrate utilization (i.e., GES-5) [5].

While the carbapenemases VIM- 1 and OXA- 48 had been reported sporadically from German pig production in recent years [6,7], other carbapenemases have not been observed in German livestock so far. Here, we report the phenotypic and genotypic properties of the first GES-5-producing E. coli from livestock. 


\section{Materials and Methods}

The E. coli isolate 19-AB02908 was obtained within the German national monitoring on antimicrobial resistance from a fecal sample of a fattening pig following the protocol of the European Reference Laboratory for Antimicrobial Resistance (EURL-AR) for selective CPE isolation (Available online: https://www.eurl-ar.eu/protocols.aspx). Phenotypic resistance was confirmed by determining minimal inhibitory concentration (MIC) values using the broth microdilution method according to CLSI guidelines (CLSI M07-A9). MIC values were interpreted according to EUCAST epidemiological cut-off values defined in 2013. Initial determination of the genotype was carried out by routine real-time PCR adapted from van der Zee et al. [8] and Swayne et al. [9], followed by diagnostic PCR for $b l a_{\mathrm{GES}}\left(\mathrm{F}: 5^{\prime}\right.$-ATGCGCTTCATTCACGCAC-3'/R: $5^{\prime}$-TCCGTGCTCAGGATGAGTTG-3') and subsequent Sanger sequencing of the PCR products. For genetic in-depth dissection, the isolate was subjected to long-read (Nanopore) and short-read (Illumina, PRJNA660949) sequencing. Hybrid assembly of the plasmid was carried out using Unicycler v.0.44 (provided by PATRIC 3.6.6). The complete plasmid sequence of pEC19-AB02908 is available under the GenBank Acc.No MT955355. Genome characterization was conducted with our in-house developed pipeline Bakcharak v1.0.0 (Available online: https://gitlab.com/bfr_bioinformatics/bakcharak) which implements ABRicate v1.0.1 (Available online: https:/github.com/tseemann/abricate) for screening of antimicrobial resistance genes (using the NCBI amrfinder database [10]), plasmid markers (using the PlasmidFinder database [11]) and virulence factors (using the VFDB [12]). Plasmid contig identification was performed using platon (Available online: https://github.com/oschwengers/platon). Furthermore the MLST sequence type was inferred using mlst (Available online: https://github.com/tseemann/mlst) based on the pubmlst database [13].

\section{Results}

The isolate 19-AB02908 was obtained from a fecal sample of a fattening pig, which was taken in the course of the German resistance monitoring on CPE. Phenotypic antimicrobial resistances were detected for all tested penicillins and cephalosporins, as well as for tetracycline (MIC $\geq 64 \mathrm{mg} / \mathrm{L}$ ), trimethoprim (MIC $>32 \mathrm{mg} / \mathrm{L}$ ), and sulfamethoxazole (MIC > $1024 \mathrm{mg} / \mathrm{L}$ ) (Table 1). The isolate further showed resistance to meropenem (MIC $\geq 0.25 \mathrm{mg} / \mathrm{L}$ ) and ertapenem (MIC $\geq 0.25 \mathrm{mg} / \mathrm{L}$ ), but only slightly reduced susceptibility to imipenem (MIC $\geq 0.5 \mathrm{mg} / \mathrm{L}$ ).

Table 1. Main characteristics of the GES-producing E. coli isolate 19-AB02908. Abbreviations of antimicrobials: AMP-ampicillin; ETP-ertapenem; FEP-cefepime, FOT-cefotaxime; FOX—cefoxitin; $\quad$ MERO—meropenem; SMX—sulfamethoxazole; $\quad$ TAZ—ceftazidime; TET_tetracycline; TMP — trimethoprim.

\begin{tabular}{|c|c|c|c|c|}
\hline Phylogeny & $\begin{array}{l}\text { Phenotypic } \\
\text { Resistance }\end{array}$ & Resistance Genes & Plasmids & $\begin{array}{c}\text { Virulence } \\
\text { Associated Genes }\end{array}$ \\
\hline $\begin{array}{c}\text {-ST1084 } \\
\text {-phylogenetic } \\
\text { group B1 }\end{array}$ & $\begin{array}{c}\text { AMP, ETP, FEP, } \\
\text { FOT, FOX, MERO, } \\
\text { SMX, TAZ, TET, } \\
\text { TMP }\end{array}$ & 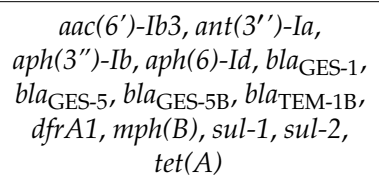 & $\begin{array}{c}12 \mathrm{~kb} \\
(\mathrm{pEC} 19-\mathrm{AB} 02908) \\
227 \mathrm{~kb}\end{array}$ & $\begin{array}{c}\text { afaA, afaD, cma, } \\
\text { cvaC, hlyF, hra, iroN, } \\
\text { iss, } \operatorname{lpfA} A, \text { ompT, sit } A, \\
\operatorname{ter} C, \text { traT }\end{array}$ \\
\hline
\end{tabular}

The results of PCR sequencing indicated the presence of a GES- 5 carbapenemase. Based on competing nucleotides at defined positions in the sequence chromatograms, the presence of up to two more GES variants seemed to be likely. The hybrid assembly of whole-genome sequencing revealed that there are three copies of the $b l a_{\mathrm{GES}}$ genes separated by $157 \mathrm{bp}$ intergenic regions on a $12 \mathrm{~kb}$ plasmid (GenBank Acc.No MT955355). The three-fold repetition of the $b a_{\text {GES }}$ genes was verified by PCR using reverse complementary primers. As initially predicted, the prevailing $b l a_{\mathrm{GES}}$ genes differed in one to two nucleotide positions from each other. One is the ESBL-encoding gene $b l a_{\mathrm{GES}-1}$, followed by $b l a_{\mathrm{GES}-5}$ and a second $b l a_{\text {GES-5 }}$ with a silent mutation on nucleotide position 54 (G54A) (Figure 1). This gene 
variant was formerly named bla $_{\mathrm{GES}-3}$ (AY494717) [14], but was later renamed to $b a_{\mathrm{GES}-5}$ on the basis of its amino acid sequence relationship [15]. The current $b l a_{\mathrm{GES}-3}$ gene (AB113580.1) was described by Wachino et al. [16]. We suggest naming the GES-5 variant with a silent mutation GES-5B according to the classifications of $b l a_{\mathrm{TEM}}$ variants. Similar structures of class-I integrons with duplicated $b l a_{\mathrm{GES}}$ variants have been found in Pseudomonas aeruginosa (GQ337064) and Enterobacter cloacae (KX230795) (Figure 1) [17,18].

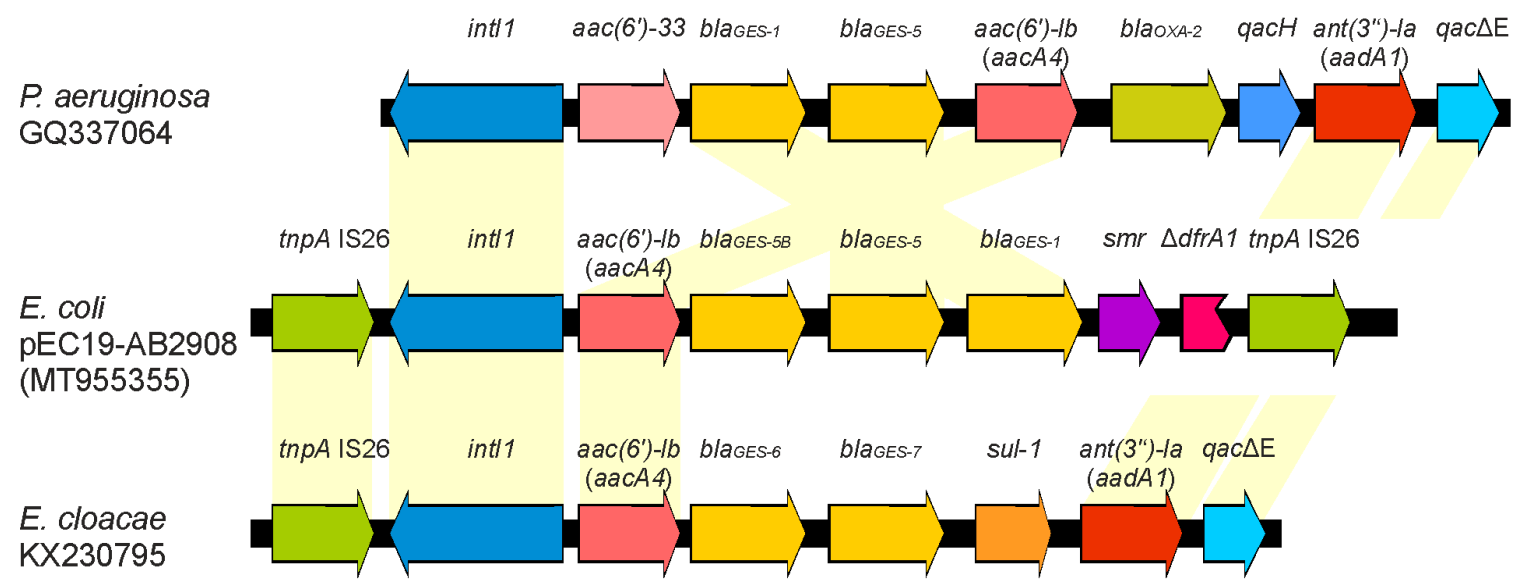

Figure 1. Comparison of the sequence organization of the $b a_{\mathrm{GES}}$ region with similar integrons available at GenBank $[17,18]$. The reading frames are presented with arrows; arrowheads indicate the direction of transcription.

Here, the unusual formation of three successive $b a_{\mathrm{GES}}$ variants was part of an incomplete integron, as the conserved CS3' region was missing. In 2018, an incomplete class-1 integron with a quadruple of $b l a_{\mathrm{GES}-5}$ gene cassettes was reported [19]. The authors suggested that the $b l a_{\mathrm{GES}}$ gene cassettes tend to duplicate by site-specific recombination. Apart from antimicrobial resistances, the plasmid backbone is represented by a DNA region of $4.7 \mathrm{~kb}$ that can be found in several Enterobacteriaceae, like Klebsiella pneumoniae (e.g., LN824137) or Salmonella Typhimurium (e.g., CP050743). It is likely that a class-I integron with two GES variants has been integrated into this small plasmid. The presence of the third bla $a_{\mathrm{GES}}$ gene might be a result of gene duplication by a recombination event in which the CS3' site of the integron was deleted. Viedma et al. [18] suggested a direct repeat sequence (5'-ACAAA- $\left.3^{\prime}\right)$ that might be involved in the gene duplication. In silico analysis revealed that this sequence is present 17 times on the pEC19-AB02908 plasmid, indicating that this recognition sequence might not be specific enough.

Besides the $b a_{\mathrm{GES}}$ carrying plasmid, the isolate harbored an additional $227 \mathrm{~kb}$ IncF plasmid conferring resistance to a variety of antimicrobials (aminoglycosides, beta-lactams, macrolides, and sulfonamides) as well as heavy metal resistance (Table 1). Therefore, a co-selection for the carbapenemase resistance can occur even if carbapenems or cephalosporins are not applied to the animals.

To determine a potential persistence of the plasmid in livestock, the farm was investigated comprehensively three months after the isolate was detected within the German national monitoring of antimicrobial resistance. Livestock and farm surrounding samples were taken and processed as described [20]. Additionally, real-time PCR from the enrichment cultures targeting the $b a_{\mathrm{GES}}$ gene was performed. However, no CPE could be detected in the samples indicating that a further spread of GES-producing enterobacteria did not occur.

Besides others, the isolate harbored a variety of virulence-associated genes typical for uropathogenic E. coli (i.e., afaA, afaD, hylF, sfaX, iroN, iss) suggesting an increased pathogenic potential [21]. This is untypical for phylogenetic group B1 as this phylogenetic group is often associated with high resistance while exhibiting only low virulence [22]. 
After VIM-1 and OXA-48, GES-5 is the third carbapenemase, which could be detected in German pig production. The entry source of these isolates remains speculative but the set of different carbapenemases found in livestock reflects the increasing diversity reported for CPE from human sources in Germany. The repeated detection of carbapenemases with presumed human origin in pig production shows that hygiene concepts should be followed. These are necessary not only to facilitate animal welfare, but also to prevent the transfer of zoonotic bacteria from humans to animals and vice versa. The newly reported isolate combines the zoonotic potential of a probable pathogenic $E$. coli with the limited therapeutic options due to its broad resistance features. This finding confirms the need for continuous monitoring in order to detect any spread of new resistance mechanisms in animal populations immediately.

Author Contributions: Conceptualization, A.I.; Methodology, A.I.; Validation, A.I., S.H.T.; Investigation, A.I., N.P.; Resources, S.H.T., J.A.H.; Data Curation, M.G.; Writing-Original Draft Preparation, A.I.; Writing-Review \& Editing, S.H.T., N.P.; M.G., A.K. Visualization, J.A.H.; Supervision, A.K.; Project Administration, A.I.; Funding Acquisition, A.K.; J.A.H. All authors have read and agreed to the published version of the manuscript.

Funding: The work of Natalie Pauly was supported by funding from the European Union's Horizon 2020 Research and Innovation programme under grant agreement No 773830: One Health European Joint Programme. The work was also supported by grants of the German Federal Institute for Risk Assessment (43-001 and 43-002).

Acknowledgments: We thank Romy Fuhrmeister and Anja Seeger for her their assistance with the farm investigations. Thanks to the farmer for taking part in this study and Dr. Torsten Jäger from the LK Harburg for his cooperation and support. We further thank Silvia Schmoger and Maria Borowiak for sequencing the isolate.

Conflicts of Interest: The authors declare no conflict of interest.

\section{References}

1. Potter, R.F.; D'Souza, A.W.; Dantas, G. The rapid spread of carbapenem-resistant Enterobacteriaceae. Drug Resist. Updat. 2016, 29, 30-46. [CrossRef] [PubMed]

2. Pfennigwerth, N. Bericht des Nationalen Referenzzentrums für gramnegative Krankenhauserreger, 2018. Epid. Bull. 2019, 31, 289-294. [CrossRef]

3. Bush, K.; Jacoby, G.A. Updated functional classification of beta-lactamases. Antimicrob Agents Chemother 2010, 54, 969-976. [CrossRef] [PubMed]

4. Poirel, L.; Le Thomas, I.; Naas, T.; Karim, A.; Nordmann, P. Biochemical sequence analyses of GES-1, a novel class A extended-spectrum beta-lactamase, and the class 1 integron In52 from Klebsiella pneumoniae. Antimicrob. Agents Chemother. 2000, 44, 622-632. [CrossRef] [PubMed]

5. Stewart, N.K.; Smith, C.A.; Frase, H.; Black, D.J.; Vakulenko, S.B. Kinetic and structural requirements for carbapenemase activity in GES-type $\beta$-lactamases. Biochemistry 2015, 54, 588-597. [CrossRef]

6. Irrgang, A.; Pauly, N.; Tenhagen, B.-A.; Grobbel, M.; Kaesbohrer, A.; Hammerl, A.J.A. Spill-Over from Public Health? First Detection of an OXA-48-Producing Escherichia coli in a German Pig Farm. Microorganisms 2020, 8, 855. [CrossRef] [PubMed]

7. Borowiak, M.; Szabo, I.; Baumann, B.; Junker, E.; Hammerl, J.A.; Kaesbohrer, A.; Malorny, B.; Fischer, J. VIM-1-producing Salmonella Infantis isolated from swine and minced pork meat in Germany. J. Antimicrob. Chemother. 2017, 72, 2131-2133. [CrossRef] [PubMed]

8. van der Zee, A.; Roorda, L.; Bosman, G.; Fluit, A.C.; Hermans, M.; Smits, P.H.M.; van der Zanden, A.G.M.; Te Witt, R.; van Bruijnesteijn Coppenraet, L.E.S.; Cohen Stuart, J.; et al. Multi-centre evaluation of real-time multiplex PCR for detection of carbapenemase genes OXA-48, VIM, IMP, NDM and KPC. BMC Infect Dis. 2014, 14, 27. [CrossRef]

9. Swayne, R.L.; Ludlam, H.A.; Shet, V.G.; Woodford, N.; Curran, M.D. Real-time TaqMan PCR for rapid detection of genes encoding five types of non-metallo- (class A and D) carbapenemases in Enterobacteriaceae. Int. J. Antimicrob. Agents 2011, 38, 35-38. [CrossRef]

10. Feldgarden, M.; Brover, V.; Haft, D.H.; Prasad, A.B.; Slotta, D.J.; Tolstoy, I.; Tyson, G.H.; Zhao, S.; Hsu, C.-H.; McDermott, P.F.; et al. Validating the AMRFinder Tool and Resistance Gene Database by Using Antimicrobial Resistance Genotype-Phenotype Correlations in a Collection of Isolates. Antimicrob. Agents Chemother. 2019, 63. [CrossRef] 
11. Carattoli, A.; Zankari, E.; Garcia-Fernandez, A.; Voldby Larsen, M.; Lund, O.; Villa, L.; Moller Aarestrup, F.; Hasman, H. In silico detection and typing of plasmids using PlasmidFinder and plasmid multilocus sequence typing. Antimicrob. Agents Chemother. 2014, 58, 3895-3903. [CrossRef] [PubMed]

12. Chen, L.; Yang, J.; Yu, J.; Yao, Z.; Sun, L.; Shen, Y.; Jin, Q. VFDB: A reference database for bacterial virulence factors. Nucleic Acids Res. 2005, 33, D325-D328. [CrossRef] [PubMed]

13. Jolley, K.A.; Maiden, M.C.J. BIGSdb: Scalable analysis of bacterial genome variation at the population level. BMC Bioinform. 2010, 11, 595. [CrossRef] [PubMed]

14. Vourli, S.; Giakkoupi, P.; Miriagou, V.; Tzelepi, E.; Vatopoulos, A.C.; Tzouvelekis, L.S. Novel GES/IBC extended-spectrum beta-lactamase variants with carbapenemase activity in clinical enterobacteria. FEMS Microbiol. Lett. 2004, 234, 209-213. [CrossRef]

15. Jeong, S.H.; Bae, I.K.; Kim, D.; Hong, S.G.; Song, J.S.; Lee, J.H.; Lee, S.H. First outbreak of Klebsiella pneumoniae clinical isolates producing GES-5 and SHV-12 extended-spectrum beta-lactamases in Korea. Antimicrob. Agents Chemother. 2005, 49, 4809-4810. [CrossRef]

16. Wachino, J.-I.; Doi, Y.; Yamane, K.; Shibata, N.; Yagi, T.; Kubota, T.; Ito, H.; Arakawa, Y. Nosocomial spread of ceftazidime-resistant Klebsiella pneumoniae strains producing a novel class a beta-lactamase, GES-3, in a neonatal intensive care unit in Japan. Antimicrob. Agents Chemother. 2004, 48, 1960-1967. [CrossRef]

17. Cuzon, G.; Bogaerts, P.; Bauraing, C.; Huang, T.-D.; Bonnin, R.A.; Glupczynski, Y.; Naas, T. Spread of Plasmids Carrying Multiple GES Variants. Antimicrob. Agents Chemother. 2016, 60, 5040-5043. [CrossRef]

18. Viedma, E.; Juan, C.; Acosta, J.; Zamorano, L.; Otero, J.R.; Sanz, F.; Chaves, F.; Oliver, A. Nosocomial spread of colistin-only-sensitive sequence type 235 Pseudomonas aeruginosa isolates producing the extended-spectrum beta-lactamases GES-1 and GES-5 in Spain. Antimicrob. Agents Chemother. 2009, 53, 4930-4933. [CrossRef]

19. Xu, T.; Wang, J.; Ying, J.; Zhu, T.; Liu, Y.; Xu, L.; Li, P.; Li, P.; Ying, J.; Li, K.; et al. Characterisation of a class 1 integron associated with the formation of quadruple blaGES- 5 cassettes from an IncP- $1 \beta$ group plasmid in Pseudomonas aeruginosa. Int. J. Antimicrob. Agents 2018, 52, 485-491. [CrossRef]

20. Irrgang, A.; Tenhagen, B.-A.; Pauly, N.; Schmoger, S.; Kaesbohrer, A.; Hammerl, J.A. Characterization of VIM-1-Producing E. coli Isolated From a German Fattening Pig Farm by an Improved Isolation Procedure. Front. Microbiol. 2019, 10, 2256. [CrossRef]

21. Sarowska, J.; Futoma-Koloch, B.; Jama-Kmiecik, A.; Frej-Madrzak, M.; Ksiazczyk, M.; Bugla-Ploskonska, G.; Choroszy-Krol, I. Virulence factors, prevalence and potential transmission of extraintestinal pathogenic Escherichia coli isolated from different sources: Recent reports. Gut Pathog. 2019, 11, 10. [CrossRef]

22. Johnson, J.R.; Murray, A.C.; Gajewski, A.; Sullivan, M.; Snippes, P.; Kuskowski, M.A.; Smith, K.E. Isolation and molecular characterization of nalidixic acid-resistant extraintestinal pathogenic Escherichia coli from retail chicken products. Antimicrob. Agents Chemother. 2003, 47, 2161-2168. [CrossRef]

Publisher's Note: MDPI stays neutral with regard to jurisdictional claims in published maps and institutional affiliations.

(C) 2020 by the authors. Licensee MDPI, Basel, Switzerland. This article is an open access article distributed under the terms and conditions of the Creative Commons Attribution (CC BY) license (http://creativecommons.org/licenses/by/4.0/). 